\title{
The need for practice management training in Canadian anesthesiology residency training programs
}

\author{
Vishal Varshney, MD, FRCPC (1)
}

Received: 3 May 2019/Revised: 6 May 2019/Accepted: 6 May 2019/Published online: 17 May 2019

(C) Canadian Anesthesiologists' Society 2019

\section{To the Editor,}

A question I felt was taboo to ask during my residency training became a question I wish I knew the answer to within my first few months of practice: so, how do you bill for that?

Certainly, talking about money and practice management (defined as the financial, legal, or administrative matters of a medical practice $)^{1}$ can be awkward, but amongst my fellow cohort of newly graduated anesthesiologists who spent our training focused on the basic science and clinical aspects of a safe and proficient practice of anesthesiology, these were questions we collectively wished we asked more about. I hypothesize that there is a substantial need for comprehensive and standardized practice management training in anesthesiology residency programs, and propose that delivery of this should become a multistakeholder effort led by the Canadian Anesthesiologist's Society (CAS).

The Royal College of Physicians and Surgeons of Canada's Objectives of Training in the Specialty of Anesthesiology state that "anesthesiologists are able to manage their practice and career effectively", yet the skills needed to achieve this are not mentioned, nor are the details of how this pertains to personal practice management, leaving significant ambiguity in how this key competency should be interpreted and delivered. ${ }^{2}$ The 2015 Resident Doctors of Canada (RDoC) National Resident Survey found that residents have limited access to structured practice management training, and that there

V. Varshney, MD, FRCPC ( $)$

Department of Anesthesiology, Perioperative and Pain Medicine,

University of Calgary, Calgary, AB, Canada

e-mail: vishal.varshney@ahs.ca is variability in both the availability and quality of this training. ${ }^{3}$ Less than $60 \%$ of non-family medicine residents reported receiving some form of practice management training, with only $10 \%$ of these residents reporting satisfaction with this training; one-third of respondents received no training at all. ${ }^{3}$ In the $2018 \mathrm{RDoC}$ survey, $70 \%$ of final-year trainees rated their understanding of billing codes within their specialty at less than $6 / 10$, and a majority $(58.1 \%)$ felt that "on the job" provided the best setting for this training. ${ }^{3}$

While almost no data exist comparing billing practices in Canada between new graduates and established physicians (especially in anesthesiology), data from the United States (US) pertaining to relative value units (measures of value used in the Medicare reimbursement formula for physician services) of new physicians suggest lower performance-based pay than established physicians, in part as a result of newer graduates needing more time to establish non-clinical aspects of their practice, such as billing and coding. ${ }^{4}$ With up to $75 \%$ of US anesthesiology and related fellowship programs having received some formal practice management education during their training, there remains a reported need for enhanced and structured practice management training. ${ }^{5}$

As our national specialist organization, the CAS would seem well-poised to lead multi-stakeholder collaboration and advocate for the delivery of a practice management curriculum for newly graduated anesthesiologists. This could be built on the principles identified by RDoC's "Principles for Practice Management Training in PGME", calling for "practice management training [that] must be delivered universally to all resident doctors, through a curriculum that is consistent, comprehensive and evidencebased, and in collaboration with relevant organizations and sectors." I recognize that the variability between 
provincial billing considerations and practice patterns across community and academic institutions might make this challenging, but the CAS could provide the national forum and mentorship opportunities to facilitate this discussion in our specialty. The "business" aspects of anesthesiology practice are widely expected to be learned, yet minimal and only informal training is usually given for these aspects. Structured practice management training has significant potential to alleviate some of the uncertainty that new graduates feel when beginning their careers as anesthesiologists.

Acknowledgement I would like to acknowledge and thank Resident Doctors of Canada for their work in obtaining the data around practice management training in Canada, and advocating for necessary changes and improvements in postgraduate medical education in Canada.

Conflicts of interest None declared.

Editorial responsibility This submission was handled by Dr. Hilary P. Grocott, Editor-in-Chief, Canadian Journal of Anesthesia.

\section{References}

1. Resident Doctors of Canada. Principles for Practice Management Training in PGME. December 2016 - Infosheet. Available from URL: https://residentdoctors.ca/wp-content/uploads/2017/09/RDOC_ PM-Principles_Infosheet-EN.pdf (accessed May 2019).

2. Royal College of Physicians and Surgeons of Canada. Objectives of Training in the Specialty of Anesthesiology. Available from URL: http://www.royalcollege.ca/rcsite/documents/ibd/anesthesiology_ otr_e.pdf (accessed May 2019).

3. Resident Doctors of Canada. 2018 National Resident Survey. Available from URL: https://residentdoctors.ca/wp-content/uploads/ 2018/10/National-Resident-Survey-2018-R8.pdf (accessed May 2019).

4. Ittner CD, Larcker DF, Pizzini M. Performance-based compensation in member-owned firms: an examination of medical group practices. J Account Econ 2007; 44: 300-27.

5. Przkora R, Antony A, Mcneil A, et al. Do pain medicine fellowship programs provide education in practice management? A survey of pain medicine fellowship programs. Pain Physician 2018; 21: E43-8.

Publisher's Note Springer Nature remains neutral with regard to jurisdictional claims in published maps and institutional affiliations. 